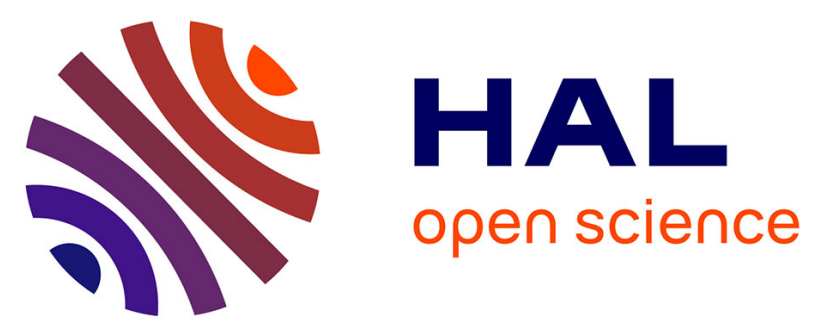

\title{
Translational Identification of Transcriptional Signatures of Major Depression and Antidepressant Response
}

\author{
Mylène Hervé, Aurélie Bergon, Anne-Marie Le Guisquet, Samuel Leman, \\ Julia-Lou Consoloni, Nicolas Fernandez-Nunez, Marie-Noëlle Lefebvre, \\ Wissam El-Hage, Raoul Belzeaux, Catherine Belzung, et al.
}

\section{To cite this version:}

Mylène Hervé, Aurélie Bergon, Anne-Marie Le Guisquet, Samuel Leman, Julia-Lou Consoloni, et al.. Translational Identification of Transcriptional Signatures of Major Depression and Antidepressant Response. Frontiers in Molecular Neuroscience, 2017, 10, pp.248. 10.3389/fpsyt.2016.00072 . hal01575031

\section{HAL Id: hal-01575031 \\ https://hal-amu.archives-ouvertes.fr/hal-01575031}

Submitted on 17 Aug 2017

HAL is a multi-disciplinary open access archive for the deposit and dissemination of scientific research documents, whether they are published or not. The documents may come from teaching and research institutions in France or abroad, or from public or private research centers.
L'archive ouverte pluridisciplinaire HAL, est destinée au dépôt et à la diffusion de documents scientifiques de niveau recherche, publiés ou non, émanant des établissements d'enseignement et de recherche français ou étrangers, des laboratoires publics ou privés. 
OPEN ACCESS

Edited by:

Nashat Abumaria

Fudan University, China

Reviewed by: Boldizsar Czeh,

University of Pécs, Hungary

Gianluca Serafini,

University of Genoa, Italy

*Correspondence:

El Chérif Ibrahim

el-cherif.ibrahim@univ-amu.fr

Received: 16 June 2017

Accepted: 24 July 2017

Published: 08 August 2017

Citation:

Hervé $M$, Bergon $A$,

Le Guisquet A-M, Leman S,

Consoloni J-L, Fernandez-Nunez N, Lefebvre M-N, El-Hage W,

Belzeaux R, Belzung $C$ and Ibrahim EC (2017) Translational Identification of Transcriptional Signatures of Major Depression and

Antidepressant Response.

Front. Mol. Neurosci. 10:248.

doi: $10.3389 /$ fnmol.2017.00248

\section{Translational Identification of Transcriptional Signatures of Major Depression and Antidepressant Response}

\author{
Mylène Hervé ${ }^{1,2}$, Aurélie Bergon ${ }^{3}$, Anne-Marie Le Guisquet ${ }^{4}$, Samuel Leman 4 , \\ Julia-Lou Consoloni ${ }^{1,2,5}$, Nicolas Fernandez-Nunez ${ }^{6}$, Marie-Noëlle Lefebvre ${ }^{7}$, \\ Wissam El-Hage ${ }^{4,8,9}$, Raoul Belzeaux ${ }^{1,2,5,10}$, Catherine Belzung ${ }^{4}$ and El Chérif Ibrahim 1,2,11 * \\ ${ }^{1}$ Aix Marseille Univ, CNRS, CRN2M UMR 7286, Marseille, France, ${ }^{2}$ FondaMental, Fondation de Recherche et de Soins en \\ Santé Mentale, Créteil, France, ${ }^{3}$ Aix Marseille Univ, INSERM, TAGC UMR_S 1090, Marseille, France, ${ }^{4}$ INSERM U930 Eq 4, \\ UFR Sciences et Techniques, Université François Rabelais, Tours, France, ${ }^{5}$ AP-HM, Hôpital Sainte Marguerite, Pôle de \\ Psychiatrie Universitaire Solaris, Marseille, France, ${ }^{6}$ TGML, Platform IbiSA, Aix Marseille Univ, INSERM U1090, TAGC, \\ Marseille, France, ${ }^{7} \mathrm{CIC}-\mathrm{CPCET}$, AP-HM, Hôpital La Timone, Marseille, France, ${ }^{8} \mathrm{CHRU}$ de Tours, Clinique Psychiatrique \\ Universitaire, Tours, France, ${ }^{9}$ INSERM CIC 1415, Centre d'Investigation Clinique, CHRU de Tours, Tours, France, ${ }^{10} \mathrm{McGill}$ \\ Group for Suicide Studies, Douglas Mental Health University Institute, Department of Psychiatry, McGill University, Montreal, \\ QC, Canada, "11 Aix Marseille Univ, CNRS, INT, Inst Neurosci Timone UMR 7289, Marseille, France
}

Major depressive disorder (MDD) is a highly prevalent mental illness whose therapy management remains uncertain, with more than $20 \%$ of patients who do not achieve response to antidepressants. Therefore, identification of reliable biomarkers to predict response to treatment will greatly improve MDD patient medical care. Due to the inaccessibility and lack of brain tissues from living MDD patients to study depression, researches using animal models have been useful in improving sensitivity and specificity of identifying biomarkers. In the current study, we used the unpredictable chronic mild stress (UCMS) model and correlated stress-induced depressive-like behavior ( $n=8$ unstressed vs. 8 stressed mice) as well as the fluoxetine-induced recovery ( $n=8$ stressed and fluoxetine-treated mice vs. 8 unstressed and fluoxetine-treated mice) with transcriptional signatures obtained by genome-wide microarray profiling from whole blood, dentate gyrus (DG), and the anterior cingulate cortex (ACC). Hierarchical clustering and rank-rank hypergeometric overlap ( $\mathrm{RRHO}$ ) procedures allowed us to identify gene transcripts with variations that correlate with behavioral profiles. As a translational validation, some of those transcripts were assayed by RT-qPCR with blood samples from 10 severe major depressive episode (MDE) patients and 10 healthy controls over the course of 30 weeks and four visits. Repeated-measures ANOVAs revealed candidate trait biomarkers (ARHGEF1, CMAS, IGHMBP2, PABPN1 and $T B C 1 D 10 C)$, whereas univariate linear regression analyses uncovered candidates state biomarkers (CENPO, FUS and NUBP1), as well as prediction biomarkers predictive of antidepressant response (CENPO, NUBP1). These data suggest that such a translational approach may offer new leads for clinically valid panels of biomarkers for MDD.

Keywords: chronic stress, depression, mRNA, blood, transcriptomics, biomarker, antidepressant 


\section{INTRODUCTION}

Major depressive disorder (MDD) is a highly prevalent mental illness characterized by altered emotional, cognitive and behavioral functions. Pathophysiology of depression is complex and is hypothesized to involve several biological processes, including neurotransmitter dysfunction, neuronal networks alteration, inadequate neuroendocrine stress response, unsynchronized circadian rhythms and chronic inflammation (Moylan et al., 2013). Major depression is therefore unlikely to have a single cause. Diagnosis of MDD still mainly relies on subjective evaluation, such as self-reporting of symptoms and clinical interviews (Young et al., 2016). Although modern pharmacological medications such as selective serotonin reuptake inhibitors (SSRIs) and more recently serotoninnorepinephrine reuptakes inhibitors (SNRIs, e.g., duloxetine), has demonstrated efficacy and potential to prevent negative consequences (such as suicidal behavior) associated with MDD (Girardi et al., 2009), the optimal therapies to manage MDD remain unclear, as more than $20 \%$ of MDD patients remain resistant to treatments and around $50 \%$ of the episodes are recurrent (Kessler, 2003; Möller, 2008). Therefore, there is a need for improvement of MDD patient medical care and identification of reliable biomarkers could help in diagnosis, classification of MDD subtypes, and monitoring of disease progression (Jentsch et al., 2015; Young et al., 2016).

The term biomarker can be understood in different ways. A biomarker can provide information about the pathophysiology of a disease, as well as be used as an objective tool to validate a diagnosis. It can also predict disease progression or provide prediction on treatment response (McMahon, 2014). Classically, the most common biomarker concepts correspond to individual features used as indicators of a disease state (diagnostic biomarker), or even predictor of clinical outcome following the treatment (treatment biomarker, Papakostas and Fava, 2008; Davis et al., 2015). Generally considered as a biological variable, a biomarker is not limited to this definition and can encompass functional tests as fMRI or surveys (Leuchter et al., 2010; Phillips et al., 2015).

Despite decades of research in the depression field, no evidence of depression-related biomarkers have been identified (Gururajan et al., 2016). Although some potential biomarkers based on biological theories of depression etiology have emerged, none are being used in clinical practice (Breitenstein et al., 2014). Difficulty in identifying candidate depression biomarkers is due to limited knowledge of depression's etiology and the absence of a phenotype attributed to a single gene in depression pathophysiology. This is further reinforced by the difficulty in studying brain dysfunctions solely by relying on peripheral biological variations. Indeed, inaccessibility to brain tissues from living MDD patients constrained research to using blood and occasionally cerebrospinal fluid to study genetic alterations in depressive subjects (Wan et al., 2015; Hestad et al., 2016), making it almost impossible to draw any direct correlations between changes observed in the brain. To overcome this issue and to extend our understanding of biological pathways mediating individual differences in behavior and risk for psychopathology of major depression, translational research has been established using animal models of depression (Joeyen-Waldorf et al., 2012; Pajer et al., 2012; Issler et al., 2014; Arloth et al., 2015; Qesseveur et al., 2016). Using this method, it is possible to test animal tissues from both central and peripheral locations, identify candidate biomarkers, and assess correlation of these marker variations of expression in accessible human MDD samples with etiological hypotheses of depression. Translational studies have the advantage of improving the sensitivity and specificity of biomarker researches (Bertsch et al., 2005). Notably, most biomarkers identification efforts for neuropsychiatric disorders have relied on transcriptomics rather than proteomics (Breen et al., 2016), the former being less expensive while yielding more exhaustive biological data than the latter.

With the goal of identifying potential diagnostic or predictive biomarkers of depression, we undertook a translational approach that correlates data from a rodent model of depression with data from human blood samples. We utilized the unpredictable chronic mild stress (UCMS) model, which has contributed to the elucidation of the pathophysiological mechanisms of depression such as decreased neurogenesis, hypothalamic-pituitary-adrenal (HPA) axis alterations and maladaptive changes in amygdala (Surget et al., 2008; Sibille et al., 2009; Nollet et al., 2013). We aimed to correlate depressive-like behavior induced by UCMS protocol and fluoxetine-induced recovery with transcriptional signatures from whole blood as well as the hippocampus and the anterior cingulate cortex (ACC), two brain regions involved in mood regulation in which dysfunction has been reported in MDD (Rive et al., 2013; Jaworska et al., 2015; Wise et al., 2016). Since the hippocampus is known to have large variations in gene expression, we focused on the dentate gyrus (DG) where adult neurogenesis has been described and linked to psychiatric illness (Kohen et al., 2014). Hierarchical clustering procedures and classical statistical threshold methods allowed us to identify potential biomarkers with variations that correlate with behavioral profile. Moreover, we uncovered statistically significant overlaps between gene expression signatures from peripheral and central tissues by applying the innovative rank-rank hypergeometric overlap (RRHO) procedure. Finally, we validated our newly identified gene candidates with blood samples from a longitudinal human cohort of severe major depressive episode (MDE) patients. These patients were free of antidepressant at baseline, and monitored over 30 weeks for disease progression.

\section{MATERIALS AND METHODS}

\section{Animals}

Thirty-two 8-week-old male BALB/c (Centre d'Elevage Janvier, Le Genest St. Isle, France) were divided into four groups. The first group (S-C, Stressed-Control, $n=8$ ) of mice was subjected to UCMS procedure for 8 weeks (Nollet et al., 2013). The second group (NS-C, No Stressed-Control, $n=8$ ) of mice was kept in standard housing conditions for 8 weeks as controls. In the third group (S-FLX, Stressed-Fluoxetine, $n=8$ ), mice were subjected 
to UCMS procedure for 8 weeks and treated in parallel by fluoxetine during the last 6 weeks. The fourth group (NS-FLX, No Stressed-Fluoxetine, $n=8$ ) of mice was unstressed but treated with fluoxetine during the last 6 weeks. Fluoxetine hydrochloride (Sequoia Research Products, Pangbourne, United Kingdom) was placed in drinking water at $120 \mathrm{mg} / \mathrm{L}$ and each mouse consumed $10-20 \mathrm{mg} / \mathrm{kg} /$ day of antidepressant treatment depending on the amount of water consumption. A diagram outlining the experimental protocol is presented in Supplementary Figure S1. At the end of the protocol, $0.5 \mathrm{~mL}$ of blood was collected from the submandibular vein and stabilized with $1.3 \mathrm{~mL}$ RNAlater ${ }^{\circledR}$ solution (Life Technologies, Ambion, Austin, TX, USA). Mice were euthanized by $\mathrm{CO}_{2}$ inhalation. Brains were rapidly extracted and microdissected to recover ACC and DG samples.

All experiments on mice were carried out according to policies on the care and use of laboratory animals of European Community legislation 2010/63/EU. The local Ethics Committee (CEEAVdL-19) approved the protocols used in this study (protocol number 2011-06-10).

\section{UCMS}

Mice from the NS-C and NS-FLX groups were housed in groups of four in standard cages, whereas the UCMS-exposed mice were isolated in individual home cages with no physical contact with other mice. The stressors used were varied and applied in a different sequence each week in order to avoid habituation (see Supplementary Materials and Methods).

\section{Mice Behavior}

Weight and coat state were measured weekly, as markers of UCMS-induced depressive-like behavior, except for the last week before sacrifice, when coat state from seven different areas of the body was recorded twice, separated by 3-day intervals (see Supplementary Materials and Methods, Supplementary Figure S1). At the end of the 8th week, a complementary test of nest building was performed just before sacrifice. The test was administered by isolating mice in their home cages (see Supplementary Materials and Methods). To assign stress susceptibility/resiliency and then extrapolate antidepressant response/nonresponse for each mouse, cutoffs were defined according to the distribution of the sum of both coat state measurements in NS-C and NS-FLX vs. S-C groups. Next, S-FLX mice were further divided into responders, S-FLX-R (sum of coat scores $\leq 2$ ), and nonresponders, S-FLX-NR (sum of coat scores $>2$ ).

\section{Human Cohort}

Ten MDE patients were selected from a larger French cohort (see Supplementary Materials and Methods). Patients were required to be free of antidepressants at baseline, and were matched for age and sex with 10 healthy controls enrolled in the south of France (Marseille) from the same cohort. Clinical assessments of both patients and controls were made at baseline (week 0), and at 2, 8 and 30 weeks after inclusion (Supplementary Table S1). All patients met the Diagnostic and Statistical Manual of mental disorders, fourth edition, Text Revision (DSM-IV-TR) criteria for MDE (American Psychiatric Association, 2000), presenting at least severe MDE (17-item Hamilton Depression Rating Scale, HDRS, score $\geq 20$ ) (American Psychiatric Association, 2008). Venous blood (8-9 $\mathrm{mL}$ ) was drawn from fasting MDE patients and healthy controls in EDTA tubes (Greiner Bio-One $\mathrm{GmbH}$, Kremsmünster, Austria) and processed within $40 \mathrm{~min}$ at inclusion (V1), 2 (V2), 8 (V3) and 30 (V4) weeks after inclusion. Blood was passed through a LeukoLOCK ${ }^{\mathrm{TM}}$ filter (Life Technologies, Ambion), to capture total leukocyte population while eliminating red blood cells, platelets, and plasma. After rinsing with phosphate-buffered saline, the filter was flushed with a RNAlater ${ }^{\circledR}$ solution to stabilize the RNA in the captured leukocytes. The filter was then stored at $-80^{\circ} \mathrm{C}$ before processing.

All experiments on human subjects were conducted in accordance to the latest version of the Declaration of Helsinki. The project was approved by the local ethics committee (CPP Sud Méditerranée II, Marseille, France, study registered under number 2011-A00661-40).

\section{RNA Isolation}

For mice samples, total RNAs were purified from the blood using the Mouse RiboPure-Blood RNA isolation kit (Life Technologies, Ambion), according to manufacturer's recommendations, and from brain samples using the mirVana miRNA isolation kit (Life Technologies, Ambion) after mechanical grinding of the tissues. For human samples, leukocytes trapped on LeukoLOCK filters were lysed with TRI reagent (Ambion) and mixed with Bromo-3-chloro-propane (Sigma-Aldrich, St. Louis, MO, USA). After centrifugation, total RNA from the aqueous phase was precipitated with ethanol and then purified on spin cartridge. After washings, total RNAs were eluted with $0.1 \mathrm{mM}$ EDTA. Both human and mice total RNA samples were subsequently submitted to DNase treatment (DNA-free ${ }^{\mathrm{TM}}$ kit, Life Technologies, Ambion, Austin, TX, USA). RNA concentration was determined using a nanodrop ND-1000 spectrophotometer (Thermo Scientific, Waltham, MA, USA). RNA integrity was assessed on an Agilent 2100 Bioanalyzer (Agilent Technologies, Santa Clara, CA, USA).

\section{Microarray Assay}

Sample amplification, labeling and hybridization onto Agilent whole mouse genome oligo microarrays (SurePrint G3 Mouse Gene Expression 8x60K Microarray v1, Agilent Technologies, Santa Clara, CA, USA) followed the one-color microarray-based gene expression analysis (Low Input Quick Amp Labeling) recommended by Agilent Technologies (see Supplementary Materials and Methods). The scanned images were analyzed with Agilent feature extraction software 10.5.1.1 using default parameters (protocol GE1_105_Dec08 and Grid 028004_D_F_20110722) to obtain background subtracted and spatially detrended processed signal intensities. Blood and brain data were independently normalized by quantile normalization using limma R/bioconductor package (v.2.16.4). All the procedures from control quality steps to normalized expression matrix data export, including normalization have 

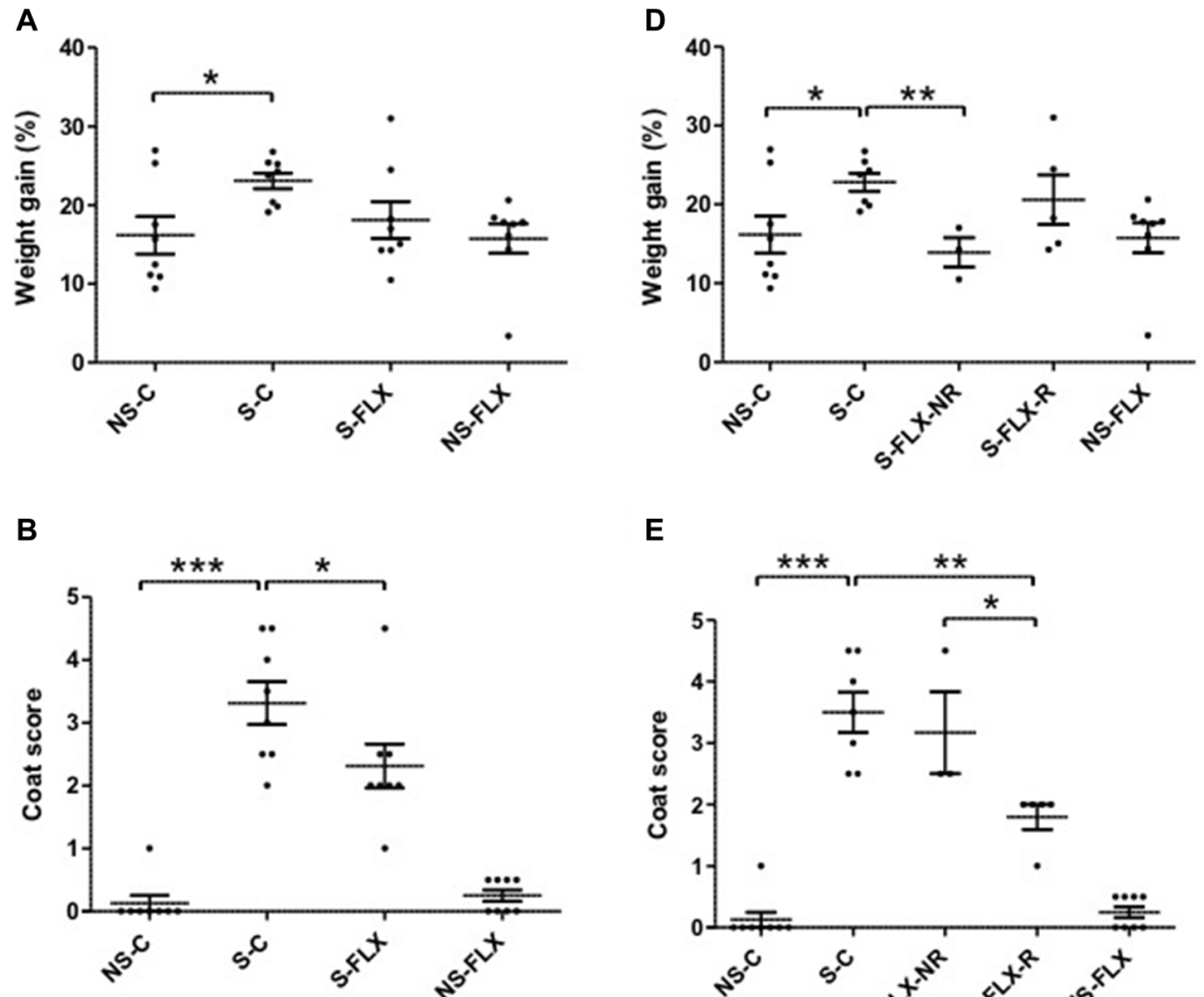

E
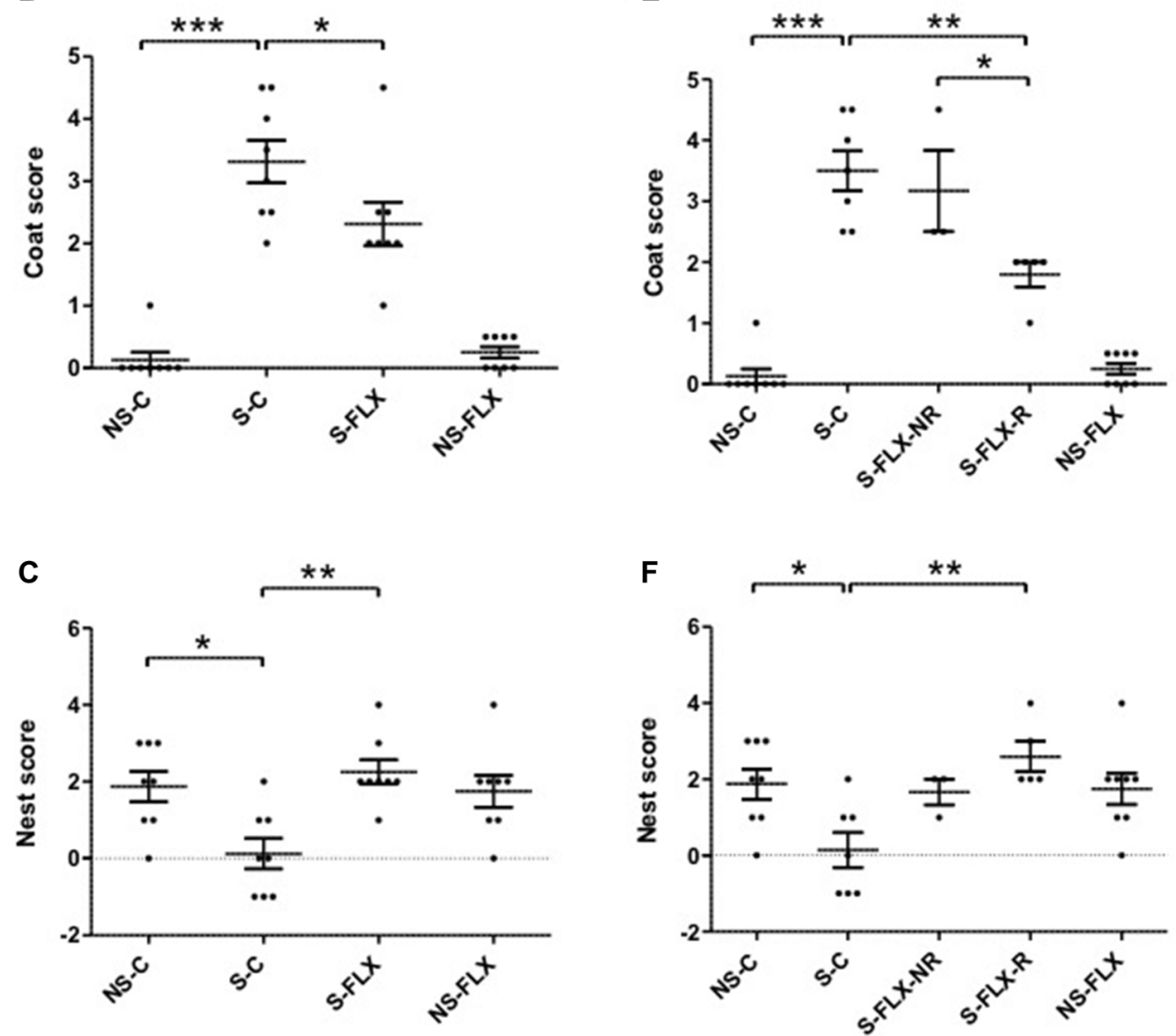

FIGURE 1 | Behavioral tests assessing depressive-like parameters. After 8 weeks of unpredictable chronic mild stress (UCMS) protocol, mice were submitted to several behavioral tests evaluating depressive-like phenotypes. Results are represented as dot plots for the four original mice groups (left panel) or after reclassification according to their responder/nonresponder phenotype (right panel). (A,D) Individual weight variation calculated after UCMS; (B,E) addition of individual coat scores obtained 3 days before sacrifice to the one at the time of sacrifice; (C-F) individual difference between nest building scores obtained after $5 \mathrm{~h}$ and $24 \mathrm{~h}$ tests. Horizontal bars denote mean values and error bars denote standard error $\left({ }^{*} P<0.05,{ }^{* *} P<0.01,{ }^{* * *} P<0.001\right.$ using parametric $t$-test (A,D) or non-parametric Mann-Whitney test (B,C,E,F)). NS, non-stressed; S, stressed; C, vehicule-treated; FLX, fluoxetine-treated; NR, nonresponder; R, responder.

been performed under R language with Limma R/Bioconductor library. The microarray data are available from the gene expression omnibus $(\mathrm{GEO})^{1}$ under the series accession number GSE84185.

\footnotetext{
${ }^{1}$ http://www.ncbi.nlm.nih.gov/geo/
}

\section{Individual Assays for mRNA Expression Quantification}

One microgram of total RNA was reverse transcribed using the High-Capacity cDNA Reverse Transcription kit (Life Technologies, Applied Biosystems, Foster City, CA, USA). Real-time PCR reactions were performed in duplicates using 
the TaqMan Universal PCR Master Mix II with no UNG (Life Technologies, Applied Biosystems) on $50 \mathrm{ng}$ of the resulting cDNA, with an ABI PRISM 7900HT thermocycler under the following conditions: $10 \mathrm{~min}$ at $95^{\circ} \mathrm{C}, 50$ cycles of $15 \mathrm{~s}$ at $95^{\circ} \mathrm{C}$ and $1 \mathrm{~min}$ at $60^{\circ} \mathrm{C}$. Primers/TaqMan probe assays purchased from Applied Biosystems were used to determine the level of expression of the mouse and human candidate genes (Supplementary Table S2). A search into the microarray data for probes showing stable expression in the stressed, non-stressed and Flx-treated animals but also blood, DG and ACC, revealed Rab5a as a moderately expressed reference gene. For human expression, we used CRYL1 as a reference gene for highly/moderately expressed genes and SV2A for weakly expressed genes (Belzeaux et al., 2012; Supplementary Table S2). Raw Ct values were obtained with manual baseline settings on the RQ Manager software (Applied Biosystems), and then the relative expression level of each mRNA was quantified by using the $2^{-\Delta \Delta \mathrm{Ct}}$ method (Livak and Schmittgen, 2001).

\section{Statistical Analysis}

\section{Microarray Data}

Fold Changes (FC) and parametric Student's $t$-tests were generated under R. Expression matrix from either blood or brain samples were analyzed using the MultiExperiment Viewer 4 (MeV4, ref version MeV_4_8_1) to generate hierarchical clustering and Significance Analysis for Microarrays (SAM) set at FDR threshold $<1 \%$. RRHO test was applied to compare patterns of gene regulation between blood and brain regions under stress application (S-C vs. NS-C) and after fluoxetine treatment (S-FLX-R vs. S-C). RRHO identifies overlap between expression profiles in a threshold free manner to assess the degree and significance of overlap (Plaisier et al., 2010). Tests looking for over- and under-enrichment were used. Full differential expression lists were ranked by the $-\log 10$ ( $P$-value) extracted from the $t$ tests multiplied by the sign of the FC. The RRHO test was used to evaluate the overlap of differential expression lists between either blood and ACC, or blood and DG, or ACC and DG. A two-sided version of the test only looking for over-enrichment was used.

\section{Behavior and Candidate Gene Validation}

Statistical analyses on behavior and molecular validation data were assessed using the IBM SPSS Statistics v20 software, with threshold $P$-value set at 0.05 . After ensuring the normal distribution of data with Shapiro-Wilk test, parametric Student's $t$-test was used for weight gain and individual gene validation on mice samples. Non-parametric Mann-Whitney test was applied for nest building scores and coat scores. Transcriptional trajectories across a 30-week follow-up were compared between human patients and healthy controls by repeated-measures ANOVAs, which allowed the comparison of candidate gene mRNAs between groups, visits and the group by visit interaction. Linear regression analyses were conducted to determine if variations of candidate gene expression in MDE patients were associated to variations of clinical score assessed with the HDRS.

\section{Ontological Analysis}

Gene lists were uploaded on DAVID (database for annotation, visualization and integrated discovery) Bioinformatics Ressources $6.7^{2}$ for identifying statistically relevant biological processes (Huang Da et al., 2009), with medium classification stringency and corrected $P$-value (Bonferroni) $<0.05$.

\section{RESULTS}

\section{Depressive-Like Behavior Is Induced by Chronic Stress and Treated by Fluoxetine}

To model appearance of depressive symptoms in MDE patients and recovery after antidepressant treatment, 16 mice were treated with UCMS protocol for 8 weeks and a second group of 16 mice were concomitantly kept in stress-free conditions. Half of each of the stressed and unstressed mice group (eight stressed and eight unstressed mice) was treated with fluoxetine during the last 6 weeks. The effects of chronic stress on susceptibility/resilience and response/nonresponse to antidepressant treatment have been evaluated by several behavioral tests. First, weight variation, one of the diagnostic criteria of depression, was measured each week. As represented in Figure 1A, all mice had gained about $15-25 \%$ of their starting weight. At the end of the UCMS protocol, stressed mice exhibited a significant increase of their weight compared to unstressed mice, which is counteracted by fluoxetine treatment (Figure 1A). In parallel, depressive-like physical alteration, assessed by the coat state score, which is a measurement of self-care, clearly distinguished unstressed mice (null or low, $\leq 1$, score) from mice exposed to chronic stress (scores 3). Such depressive behavior was partly reversed by fluoxetine treatment (Figure 1B). Furthermore, evaluation of coat state score confirmed that stress protocol was mild in intensity as maximal scores along the 8-week monitoring never exceeded 2.5 in stressed mice (Supplementary Figure S2A). Loss of motivation/apathetic behavior was evaluated with the nest-building test a week before sacrifice. As observed in Figure 1C, stressed mice exhibited an important reduction of nest building score compared to unstressed mice, and fluoxetine treatment restored normal activity. Taken together, these results confirmed depressive-like behaviors induced by chronic mild stress in mice and its reversibility with chronic fluoxetine treatment.

\section{Blood Transcriptional Profiles Reflect Behavioral Variations within Groups of Mice}

To identify potential biomarkers of a depressive-like state in mice, we conducted a genome-wide transcriptome analysis on all RNA samples extracted from blood and the DG and ACC regions of the brain, both of which play major roles in emotion processing and are known to be altered in affective disorders (Jaworska et al., 2015). Processing of the raw data resulted in 17,368 analyzable probes for blood and 33,264 probes for each

\footnotetext{
${ }^{2}$ https://david.ncifcrf.gov/
} 
brain region. Interestingly, we observed that the mean probe expression level was 2-3 fold higher in brain compared to blood samples (Supplementary Figure S3). Therefore, we separately analyzed blood and brain data to overcome any information that may be lost during normalization procedures of microarray data.

First, we tested the concordance between transcriptional data and the procedures applied to each mouse by performing an unsupervised partitioning of tissue microarray data using the $\mathrm{MeV}$ software. Figure 2A shows that, globally, each group of mice possesses a specific molecular signature in the blood that makes it different from other groups. This indicates that a blood molecular profiling can identify depressive-like phenotypes. The same evaluation conducted with brain signatures provided less clear-cut distinction between mice groups, especially for DG (Supplementary Figures S4A,B). Of note, some mice displayed a very different transcriptional pattern compared to other mice of the same group (Figure 2A, Supplementary Figures S4A,B). In addition, an internal dichotomous profile seemed to emerge within the stress and fluoxetine-treated mice that may be related to the different susceptible/resilient and responder/nonresponder phenotypes. Thus, the S-FLX mice were separated into two subcategories, as either responder (S-FLX-R, $n=5$ ) or nonresponder (S-FLX-NR, $n=3$ ) based on positive (coat score $\leq 2$ ) or negative (coat score $>2$ ) response to fluoxetine treatment, respectively (Supplementary Table S3). In addition, one mouse, with a very distinct transcriptional pattern was removed from the S-C $(n=7)$ group. With this new classification, behavioral test results had a good correlation with scores and fluoxetine response (Figures 1D-F). Moreover, when examining how coat score evolved during the 6 weeks of antidepressant treatment in stressed mice, it appeared that responder mice demonstrated weaker maximal coat score than nonresponder animals (Supplementary Figure S2B), suggesting that the responder mice are more resilient to stress. Finally, to reflect a better molecular homogeneity within mice groups, we integrated our new mice classification into a supervised partitioning of transcriptional signatures using the same probes we used for the unsupervized clustering (Figure 2B, Supplementary Figures S4C,D).

\section{Identification of Potential Biomarkers using Threshold Method Analysis}

To define state or trait biomarkers, for each tissue, we selected genes whose expression levels are modulated $(P<0.05)$ under stress (i.e., S-C vs. NS-C mice groups), and reversed by fluoxetine treatment (i.e., S-FLX-R vs. S-C mice groups). We also excluded genes whose expression varied under fluoxetine treatment without stress. Using this approach, no gene was shared by the three tissues, and only a poor overlap $(<2 \%)$ existed between two tissues (Figure 3A and Supplementary Table S4A). Similarly, when the same lists were analyzed for gene ontology enrichment, no overlap could be found between all three tissues. Whereas DG could not reveal any significantly enriched biological process, only one was found for ACC relating to factors involved in gene expression: "non-membrane-bounded organelle" (Figure 3D).

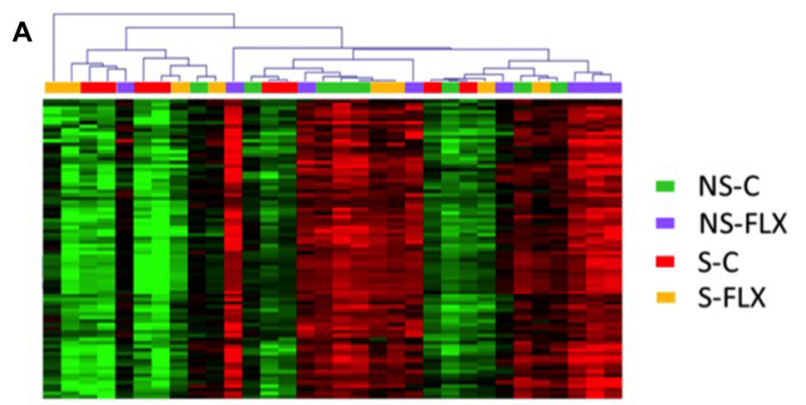

B
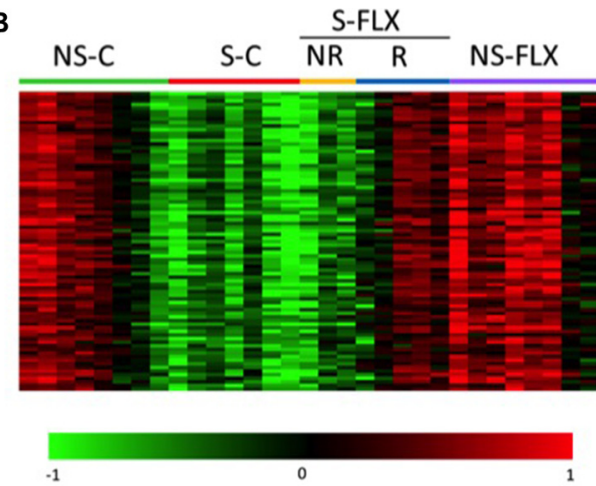

FIGURE 2 | Heatmap representation of gene expression level in blood. Heatmap of 83 gene probes whose blood signature discriminate groups of mice. Overexpressed probes are in red and underexpressed in green. Normalized signal intensities were treated using the MultiExperiment Viewer (MeV) software by applying significance analysis for microarrays (SAM) test in unsupervised mode (A) or supervised mode based on the five reclassified groups (B).

Biological processes enriched in blood include the ontological categories "ribonucleoprotein complex", "nucleotide binding", and "RNA processing", in addition to processes frequently associated to depression such as "immune system development", "ubiquitin-mediated proteolysis" and "mitochondrion" (Figure 3C).

From the dysregulated in both blood and ACC (18 genes), and blood and DG (nine genes), we found five and three genes (Supplementary Table S4A, underlined genes), respectively, that were also dysregulated in a previous transcriptome analysis we conducted from blood samples from MDE patients and healthy controls (Belzeaux et al., 2012). We selected among them, TBC1 domain family member 10C (Tbcad10c) and Centromere protein $\mathrm{O}$ (Cenpo) genes (for convergence between blood and DG) as well as the Rho guanine nucleotide exchange factor 1 (Arhgef1) and Poly(A) binding protein 1 (Pabpn1) genes (for convergence between blood and ACC) as candidate biomarkers (Figure 3A and Supplementary Table S4A, bold genes). Since our main goal was to identify blood biomarkers for clinical use, we further focused on blood data (the 1498 dysregulated genes, Figure $3 \mathbf{A}$ ) and retained only the 70 ones with FDR $<1 \%$ by SAM analysis of (NS-FLX + S-FLX-R) vs. (S-C + S-FLX-NR) groups of mice (Supplementary Table S5). Among these genes, 22 were also dysregulated in our previous transcriptome analysis 


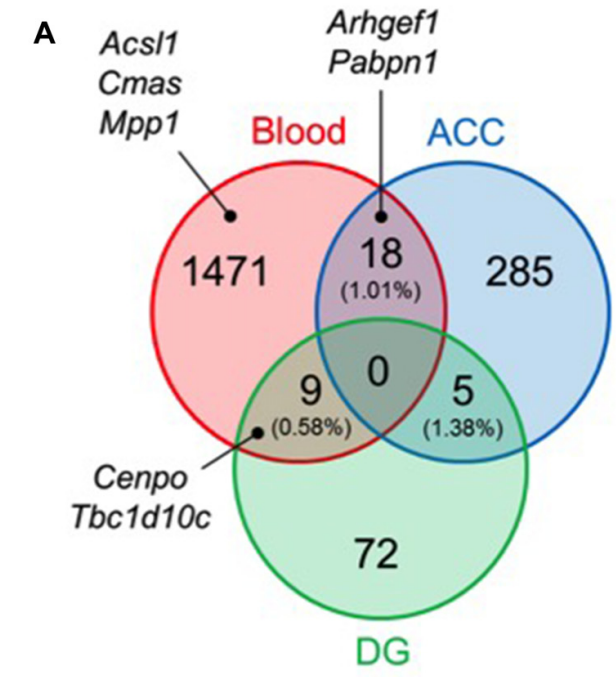

C

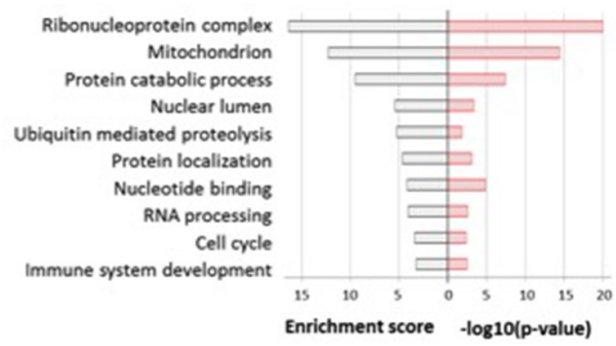

B

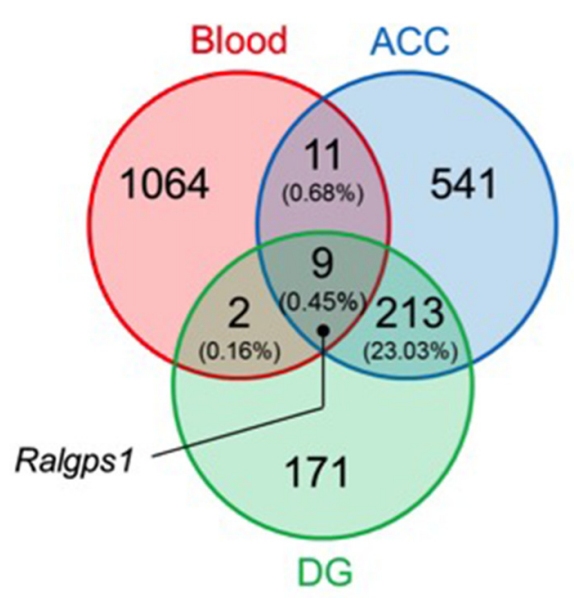

D

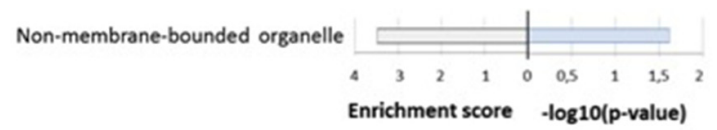

FIGURE 3 | Selection of candidate genes according to convergent fold changes (FC) dysregulation between tissues. Venn diagrams represent overlap of significant dysregulated genes in blood and brain tissues under stress and fluoxetine $(P<0.05)$ treatment $(\mathbf{A})$ or under stress condition only $(P<0.01$ and $\mathrm{FC}>1.2) \mathbf{( B )}$. Enriched gene ontology terms from the lists of dysregulated genes under stress and fluoxetine treatment $(P<0.05)$ in blood $(\mathbf{C})$ and anterior cingulate cortex $(A C C)$ (D). For each scheme, enrichment score is indicated on the left side and -log10(P-value) on the right side.

on human blood samples (Belzeaux et al., 2012; Supplementary Table S5, underlines genes). Using this method, we selected the Acyl-CoA synthetase long-chain family member 1 (Acsl1), Cytidine monophosphate $\mathrm{N}$-acetylneuraminic acid synthetase (Cmas), and Membrane palmitoylated protein 1 (Mpp1) as candidate genes underexpressed after stress and restored to basal level after fluoxetine treatment in responder mice (Figure 3A and Supplementary Table S5, bold genes). In addition, with the goal of finding blood biomarkers reflecting brain alterations, we also refined the selection parameters by focusing on genes specifically dysregulated by stress conditions by setting $P$-value threshold at 0.01 and FC $>1.2$ (Figure 3B and Supplementary Table S4B). We uncovered nine common dysregulated genes and we selected Ral GEF with PH domain and SH3 binding motif 1 (Ralgps1) as a potential candidate biomarker (Figure 3B and Supplementary Table S4B, bold genes).

Next, to validate expression dysregulations of these eight candidate genes, we performed individual RT-qPCR experiments on our mice samples. Results were normalized by Rab5a, a reference gene that was selected due to its stability in all groups of mice according to our transcriptome data. For all the eight tested candidate genes, we confirmed a stress-induced dysregulation reversed in responder mice by fluoxetine in blood tissue (Figure 4). Interestingly, these variations in blood (Figure 4) appeared to match behavioral observations (Figure 1), supporting the fact that a peripheral molecular signature is able to reflect a behavioral phenotype.

\section{Identification of New Potential Biomarkers using RRHO Method}

Previous identification of biomarkers employed classical techniques to identify significantly dysregulated genes by setting a differential expression threshold. Unfortunately, this method reduces sensitivity and hides synchronous changes between tissues that are small to moderate in global intensity. A low degree of convergence was observed among dysregulated genes in the central and peripheral mice tissues that we explored. Nevertheless, one would expect from ideal peripheral biomarkers that they reflect systemic modifications. RRHO is a recent technique developed to analyze rank changes using a threshold-free algorithm and to highlight genes 


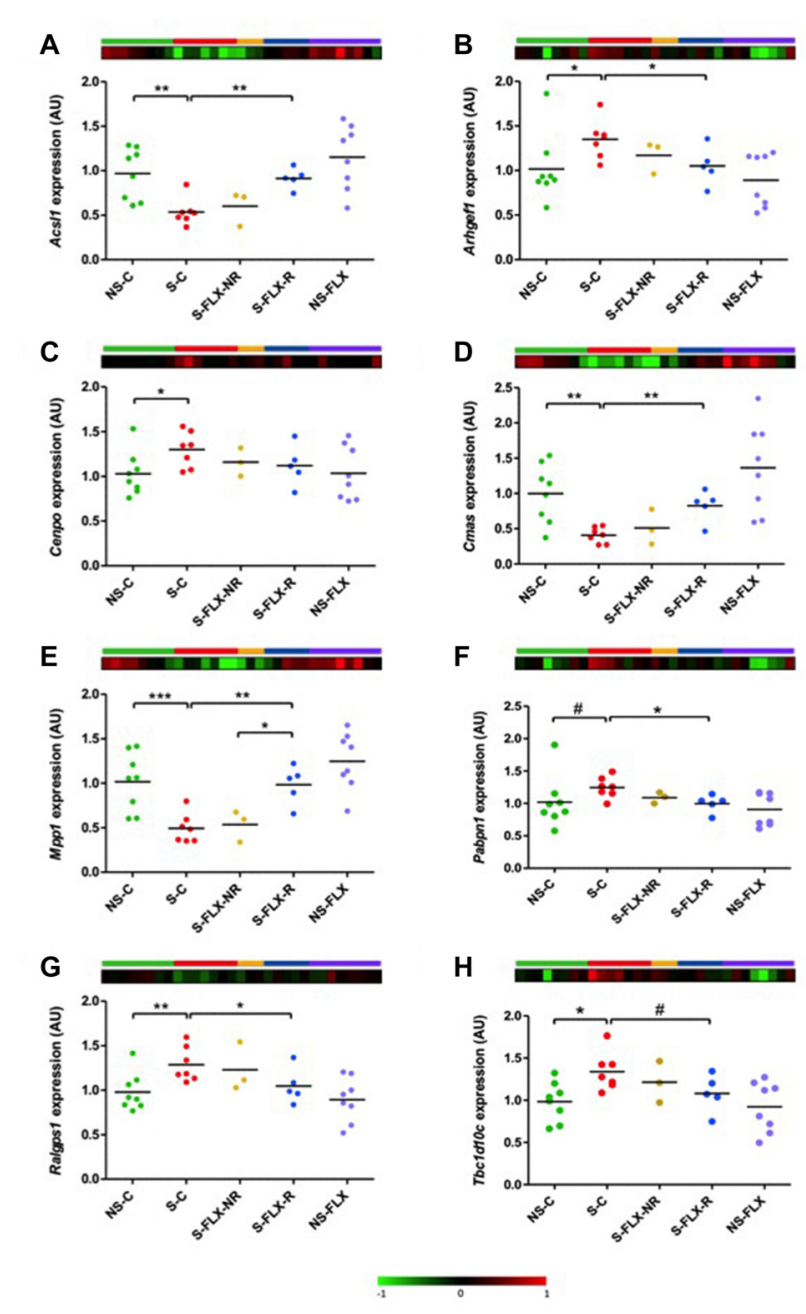

FIGURE 4 | Validation of candidate gene expression in mice blood. Dot plots represent mean of expression of Acs/1 (A), Arhgef1 (B), Cenpo (C), Cmas (D), Mpp1 (E), Pabpn1 (F), Ralgps1 (G) and Tbc1d10c (H) on mice blood samples analyzed by individual RT-qPCR. Mean of No Stressed-Control (NS-C) samples was used as a calibrator and Rab5a as a reference gene. Statistical analysis was realized using parametric $t$-test $\left({ }^{\#} P<0.1,{ }^{*} P<0.05\right.$,

$\left.{ }^{* *} P<0.01,{ }^{* * *} P<0.001\right)$. Heatmaps represent expression variation of the most significant microarray probe for each candidate gene.

presenting similar expression variations between several tissues (Plaisier et al., 2010; Bagot et al., 2016). We applied the RRHO technique on our data to study significant overlap between blood and brain gene expression signatures. Under conditions of stress (i.e., S-C vs. NS-C), we identified a robust overlap between ACC and DG $(\max -\log 10(\mathrm{P}$-value $)=957)$ in genes upregulated in both brain regions (Figure 5A). On the other hand, overlap between the results from blood and DG or ACC appeared to be weaker $(\max -\log 10(\mathrm{P}$-value $)=149$ and 47 , respectively $)$. In parallel, in mice treated with fluoxetine (i.e., S-FLX-R vs. $\mathrm{S}-\mathrm{C}$ ), a more modest overlap was obtained between ACC and DG $(\max -\log 10(\mathrm{P}$-value $)=239)$ in genes commonly upregulated or downregulated in both of the brain regions, and no overlap was detected between blood and brain tissues (max $-\log 10(\mathrm{P}$-value $)=2$ and 7 , respectively; Figure 5B). So, in our hands, the RRHO technique improved the ability to uncover shared gene expression variations between tissues. New lists of overlapping genes brought us access to potential biomarkers. We first selected genes with expression variations positively correlated between all three tissues, and varied in opposite ways under stress alone and after fluoxetine response. We identified 15 candidates (5 overexpressed and 10 underexpressed in $\mathrm{S}-\mathrm{C}$ vs. NS-C comparison; Supplementary Table S6A). We identified Cenpo, Mpp1 and Tbc1d10c which were genes also dysregulated in our previous human transcriptome data (Belzeaux et al., 2012; already validated from the classical threshold method selection) and identified three additional candidates: Fused in sarcoma (Fus), Immunoglobulin mu binding protein 2 (Ighmbp2), and Nucleotide binding protein 1 (Nubp1) for validation (Supplementary Table S6A, bold genes). Secondly, we extracted genes whose expression variations were negatively correlated between blood and the brain, and were different between S-C and NS-C mice groups. By analyzing gene ontology terms from the candidate gene lists reflecting blood-DG or blood-ACC inverted correlation (Supplementary Table S6B), we observed an enrichment for ribosomal components (Figures 5C,D). Of note, the threshold method and RRHO analyses brought out ribosomal and chromosomal factors as involved in systemic response to fluoxetine after chronic stress. Next, among the 19 candidates reflecting blood-DG inverted correlation (Supplementary Table S6B), we selected Ribosomal protein L35a (Rpl35a) for validation. Of the 106 candidates highlighting blood-ACC inverted correlation (Supplementary Table S6B), we selected Hexokinase 1 ( $H k 1)$ and Nascent polypeptide-associated complex alpha subunit (Naca) for validation. Of these six candidate genes, RT-qPCR assay on blood tissues revealed that Ighmbp2, Nubp1 and Rpl35a were indeed dysregulated by stress and restored in normal levels in responders to fluoxetine. A trend to recovery was observed for Fus and Hk1 (Figure 6), whereas the level of expression of Naca amplicon was too low to be analyzed (data not shown).

\section{Correlation between Stressed Mice and MDE Patients}

Identification of biomarkers in a depression mice model and the translation of these biomarkers to human clinical practice constitute an important goal in biological psychiatry. Consequently, we evaluated if our previous results were transposable to human subjects. We already knew, according to our selection procedure, that some of our candidate genes were dysregulated in human MDE patients compared to controls in a naturalistic cohort. In fact, among the 13 candidate genes tested for validation in mice tissues, 11 were dysregulated in human blood samples of MDE patients (Supplementary Table S7). To extend the similarity between the murine protocol and human disease, we chose to test all validated candidate genes in mice blood samples in samples of severe MDE patients free of antidepressant treatment at inclusion $(n=10)$, as well as on age- and sex-matched healthy controls $(n=10)$. In addition to assess the possibility of either a predictive or a monitoring value of candidate gene expression, we assayed RT-qPCR expression 


\section{A}

S-C vs. NS-C
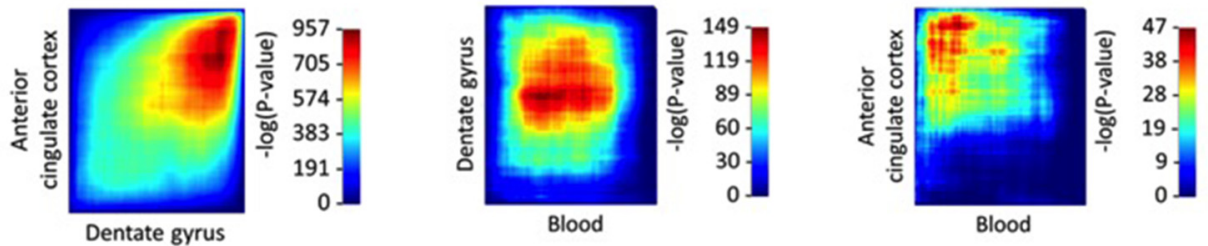

B

S-FLX-R vs. S-C
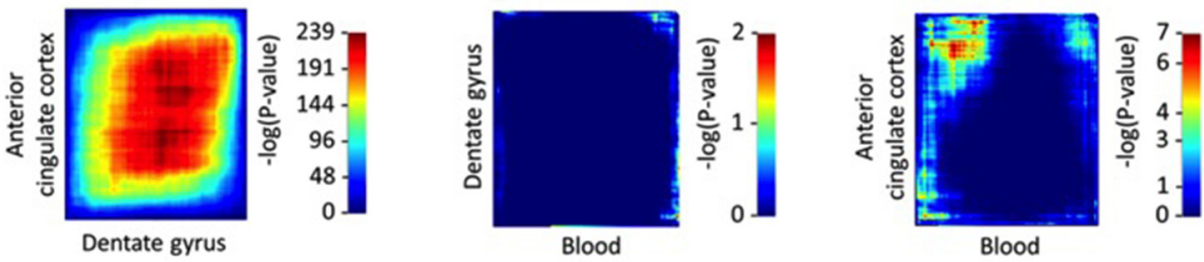

C
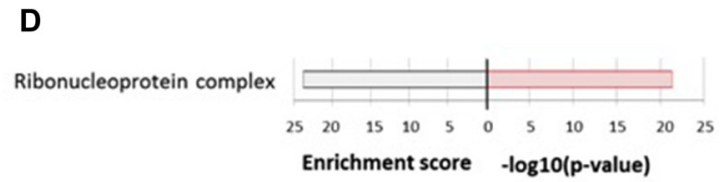

FIGURE 5 | Inter-tissue differential expression pattern of transcriptional signatures under stress or fluoxetine treatment. Rank-rank hypergeometric overlap (RRHO) maps compare threshold-free differential expression between pairs of tissues (ACC-DG, left panel; blood-DG, middle panel; blood-ACC, right panel) after stress protocol (A) or with fluoxetine treatment (B). Significance overlap was assessed by a hypergeometric test, color-coded. Enriched gene ontology terms from lists of the most co-dysregulated genes in NS-C vs. S-C (Supplementary Table S6B) in blood and dentate gyrus (DG) (C) and blood and ACC (D). For each scheme, enrichment score is indicated on the left side and -log10(P-value) on the right side.

along a 30-week monitoring corresponding to four visits: V1 (baseline), V2 (2 weeks later), V3 (8 weeks later) and V4 (30 weeks later). Among the 13 tested candidate genes (Figure 7A and Supplementary Figure S5), six genes may potentially be trait biomarkers for MDE, as they exhibited a trend or a significant variation that distinguishes the depressive and non-depressive individuals after ANOVA of repeated measurements (ARHGEF1, $F=16.2, P=0.00097, \eta^{2}=0.504 ; C M A S, F=6.60, P=0.021$, $\eta^{2}=0.292 ; I G H M B P 2, F=13.2, P=0.0022, \eta^{2}=0.452 ; M P P 1$, $F=3.35, P=0.082, \eta^{2}=0.177 ; P A B P N 1, F=7.63, P=0.014$, $\eta^{2}=0.323$ and TBC1D10C, $F=4.86, P=0.043, \eta^{2}=0.233$ ), while no effect of the visit alone or its interaction with the group was observed. Also, a trend for significance was obtained for ACSL1 (Supplementary Figure S5) when considering both group distinction $\left(F=3.20, P=0.092, \eta^{2}=0.167\right)$ as well as interaction between the group and the visit parameters $(F=2.35, P=0.084$, $\left.\eta^{2}=0.128\right)$.

To go further into the applicability of the potential biomarkers identified with the UCMS mouse model, we surmised the existence of a direct correlation between the variation of expression level of candidate genes and the evolution of the disease severity in MDE patients assessed with the HDRS score. Thus, we used with linear regression to study the candidate gene expression variation from baseline to the 8-week visit with the HDRS score variation during the same period. As shown on Figure $\mathbf{7 B}$, strong associations were found for ARHGEF1 $(b=9.48 ; 95 \%$ CI $[3.69,15.27] ; P=0.005), C E N P O(b=10.85$; 95\% CI $[1.75,19.95] ; P=0.025)$ and NUBP1 $(b=-22.78$; 95\% CI $[-38.30,-7.25] ; P=0.010)$, whereas a trend was obtained for FUS ( $b=-12.34$; 95\% CI [-24.89, 0.22]; $P=0.053$; Supplementary Figure S6). We then wondered whether candidate gene expression during the first 2 weeks of follow-up could be predictive of clinical score outcome at 8 weeks. Accordingly, variation of CENPO ( $b=13.08 ; 95 \%$ CI $[1.56,24.60] ; P=0.031)$ and NUBP1 $(b=-14.79 ; 95 \%$ CI $[-23.28,-5.77] ; P=0.005)$ expression supported their potential as treatment biomarkers (Figure 7C).

\section{DISCUSSION}

In the present work, we used a rodent model of major depression to show that whole blood transcriptional signatures provide a mirror to behavioral symptoms, including the response to antidepressant therapeutics. The venous signatures appeared superior to those of specialized brain regions, DG and ACC, known to be involved in the control of emotion and affective behaviors. Such an important observation reminds us that the correct and rapid recognition/treatment of a disabling condition such as MDD is an absolute imperative for the whole community (Girardi et al., 2009). Because obtaining of blood samples is easy 


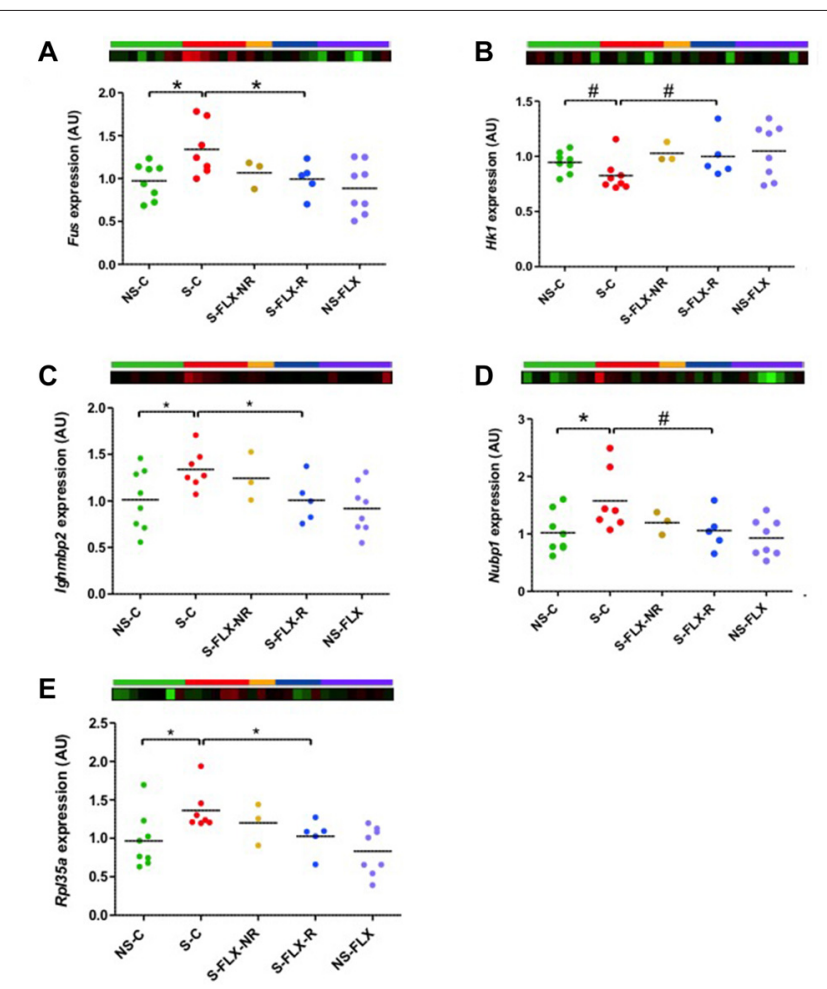

FIGURE 6 | Validation of RRHO candidate gene expression in mice blood. Dot plots represent mean of expression of Fus (A), Hk1 (B), Ighmbp2 (C), Nubp1 (D) and $R p / 35 a$ (E) in mice blood samples analyzed by individual RT-qPCR. Mean of NS-C samples was used as a calibrator and Rab5a as a reference gene. Statistical analysis was realized using parametric $t$-tests $\left({ }^{\#} P<0.1\right.$, $\left.{ }^{*} P<0.05\right)$. Heatmap represent expression variation of the most significant probe for each gene from the microarray data.

and rapid, we think that such procedure should be incorporated as a routine for improving the interpretation of future clinical trials as well as for daily practice and decision of the psychiatrist to adapt antidepressant treatment and progressively reach a personalized medicine.

Only a few previous studies compared gene expression patterns between peripheral and central tissues in rodent models of psychiatric disorders. Daskalakis et al. (2014) demonstrated convergent signaling pathways between the blood and the brain (amygdala and hippocampus) associated with trauma-related individual differences in a rat model of posttraumatic stress disorder. Apart from a recent study comparing gene expression alterations in the medial prefrontal cortex and blood cells of ovariectomized mice subjected to chronic mild stress (Miyata et al., 2016b), to our knowledge, our study is the first to report central and peripheral transcriptional signatures associated with response to antidepressant treatment in an animal model of major depression.

Recently, translational studies have been conducted to trigger the discovery of protein-coding transcriptional markers that would play a role in the balance between susceptibility and resilience to acute and chronic signals involved in depressive symptoms (Pajer et al., 2012; Malki et al., 2015; Bagot et al., 2016; Miyata et al., 2016a,b). In a series of experiments,
Redei et al. (2014) used genetic models of depression and chronic stress on different strains of rats to separately profile transcriptional signatures of depression in the brain and the blood, and test whether a subset of transcripts that differentiated depressed-like rats from non-depressed-like rats would also differentiate human patients with early-onset MDD from those without any disorder. The same gene candidates were tested for their capacity to follow and predict response to a cognitive behavioral therapy (Andrus et al., 2012; Pajer et al., 2012; Redei et al., 2014; Redei and Mehta, 2015; Mehta-Raghavan et al., 2016). Although characteristics of the animal model we used and that of our human validation cohort were different, it turned out that some variations in transcriptional signatures were shared between the different animal models and the human cohorts. For example, CMAS, encoding cytidine monophosphate $\mathrm{N}$-acetylneuraminic acid synthetase, regulates brain sialylation, which is important for the development of brain structure and function (Yoo et al., 2015). CMAS was among the short list of blood-based biomarkers from the Redei et al. (2014) studies, as well as among the candidate gene list from a transcriptome analysis on a naturalistic cohort of MDE patients responding to antidepressant treatment (Belzeaux et al., 2012). CMAS is also part of the most dysregulated transcripts in the UCMS procedure between stressed mice responding to fluoxetine and stressed mice that were either untreated or not responding to fluoxetine (Supplementary Table S5). Our qPCR results on a validation cohort of MDE patients untreated at baseline, and demonstrating a constant different pattern of expression between patients and healthy controls along remission and antidepressant treatment, could provide to CMAS the status of a trait marker for MDD (Figure 7).

To select gene candidates after microarray hybridization, we relied on both the classical method of arbitrary thresholds of differential expression between the groups of mice but also on a more innovative RRHO procedure that allows us to identify patterns of overlap between gene expression profiles among two tissues (Plaisier et al., 2010). Such method has recently been used to highlight adaptive gene networks in brain involved in stress and depression susceptibility (Bagot et al., 2016; Descalzi et al., 2017). Importantly, among the top co-dysregulated processes involved in resiliency/susceptibility to depression was the ribosome. It has also been observed from work on postmortem brains of individuals with major psychiatric disorders that protein synthesis, essentially through dysregulation of ribosomal genes and messenger RNA processing, was a pathway of central importance to psychiatric health (Darby et al., 2016). Our own results are convergent with these findings, with the addition of ubiquitin-mediated proteolysis (Figures 3C, 5C), that has also been previously regarded as crucial in the antidepressant treatment response in both mice and humans (Park et al., 2017). Thus, our candidate gene list contained two players involved in the translational machinery: the immunoglobulin mu-binding protein 2 (IGHMBP2), encoding a DNA/RNA helicase (De Planell-Saguer et al., 2009), and RPL35A, encoding a component of the large subunit of the ribosome. RPL35A was found to be among the most ubiquitinated proteins during senescence (Bengsch et al., 2015). In addition, we noticed that among our 
A
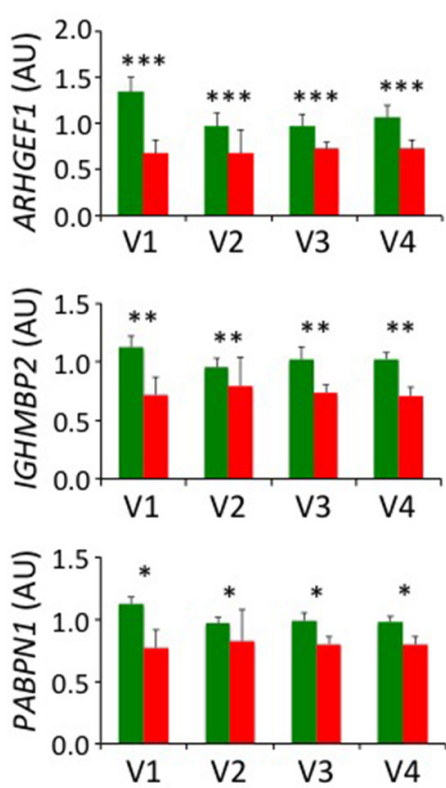

B
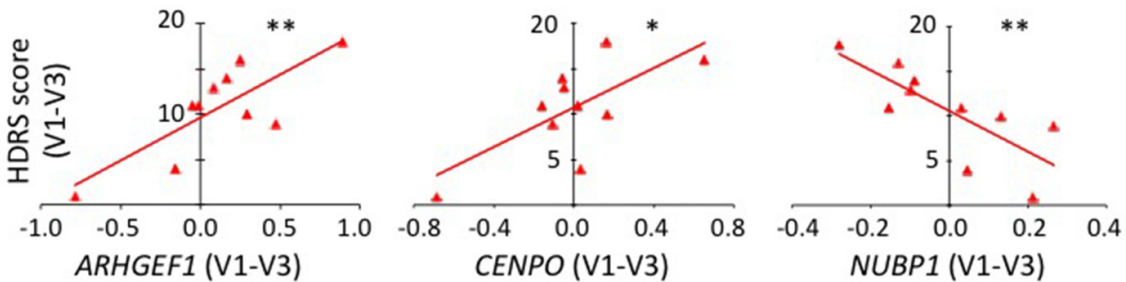

C

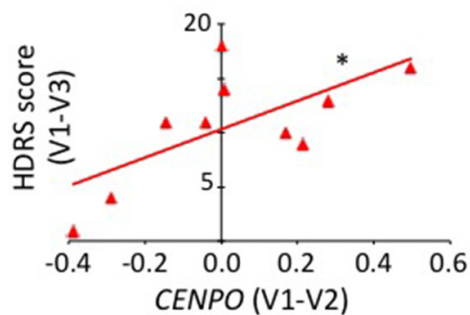

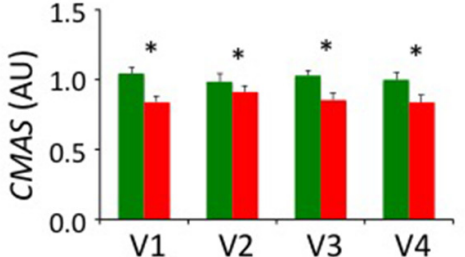

Healthy controls

MDE patients

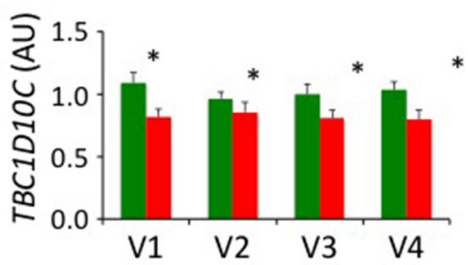

FIGURE 7 | Validation of candidate gene expression in human blood. (A) Histograms represent mean of expression of ARHGEF1, CMAS, IGHMBP2, PABPN1 and TBC1D10C on human blood. RT-qPCR data were calibrated by the mean of control samples at the four visits and normalized using CRYL1. Error bars denote standard error. Statistical analysis was realized using ANOVA of repeated measurements $\left({ }^{*} P<0.05\right.$, ${ }^{* *} P<0.01$, $\left.{ }^{* * *} P<0.001\right)$. (B) Graphs represent linear regression analysis $\left({ }^{*} P<0.05,{ }^{* *} P<0.01\right.$ ) between the variation of gene expression in major depressive episode (MDE) patients along the first 8 -week of follow-up (V1-V3) and the variation of HDRS score during the same period of time for ARHGEF1 (left panel), CENPO (middle panel) and NUBP1 (right panel). (C) Graphs represent linear regression analysis $\left({ }^{*} P<0.05,{ }^{* *} P<0.01\right)$ in MDE patients between the variation of gene expression along the first 2 -week of follow-up (V1-V2) to predict the variation of HDRS score during the first 8-week of follow-up (V1-V3) for CENPO (left panel) and NUBP1 (right panel).

lists of gene transcripts dysregulated by chronic stress in mice $(P=0.01$, data not shown $)$, and also differentially expressed between MDE patients responding to treatment and healthy controls $(P=3.9 \mathrm{E}-08)$, the RPL24 gene was listed among 6 genes predicting remission prior to antidepressant treatment for two North American cohorts of MDD patients treated with citalopram (Guilloux et al., 2015). Among genes involved in mRNA processing, our list of biomarker candidates also included FUS, encoding a multifunctional protein component of the heterogeneous nuclear ribonucleoprotein complex involved in pre-mRNA splicing and the export of fully processed mRNA to the cytoplasm. We also included $P A B P N 1$, encoding an abundant nuclear protein that binds to nascent poly(A) tail to control its size.

Of the 13 identified genes that we tested for biomarker validation in human MDE patients, one of the genes $H K 1$ has been previously linked to mood and psychotic disorders. HK1 encodes hexokinase 1, an initial and rate-limiting enzyme of 
glycolysis (Regenold et al., 2012). It has been known that genes associated with energy production are altered in postmortem brains as well as in peripheral tissues of MDD patients (Sibille et al., 2004; Klempan et al., 2009; Tobe, 2013; Garbett et al., 2015), and that molecular entities that are part of glycolysis pathway and the mitochondria in general serve as biomarkers and potential therapeutic targets for diagnosis and treatment of depression (Gormanns et al., 2011). Therefore, it was not surprising that the biological processes of the mitochondria are shared by the blood and the brain and are differentially regulated by chronic stress and fluoxetine treatment (Figure 3C). Another gene candidate that we tested, ACSL1 (Acyl-CoA Synthetase Long-Chain Family Member 1), encodes an isozyme of the long-chain fatty-acidcoenzyme A ligase family and playing a key role in lipid biosynthesis and fatty acid catabolism. Cardiovascular disease is a major comorbidity of major depression and most MDD patients have unfavorable lipid profiles, likely through the effects of stress exposure (Chuang et al., 2010). We also tested the expression of TBC1D10C, which encodes a protein demonstrated to bind and inhibit Ras and Calcineurin (involved in the mechanism of action of antidepressants (Crozatier et al., 2007; Seimandi et al., 2013)). Such binding inhibits stress signaling but also plays a role in enhancing exercise capacity and survival (Volland et al., 2016). Furthermore, the possible role of cytoskeleton dysfunction in the pathogenesis of major depression has been already reviewed (Wong et al., 2013). We were interested in MPP1, which encodes a protein that helps microtubule polymerization during cell division and is also involved in remodeling the cytoskeletons of neurons (McNeely et al., 2017). RALGPS1 and ARHGEF1 are two gene candidates with yet unknown function but were also found to be dysregulated in both blood and brain tissues (Figures 3A,B). They belong to the family of guanine nucleotide exchange factors that participate in a broad range of cellular processes such as proliferation, differentiation and migration. Perhaps the most interesting gene candidates from our survey are the putative prediction biomarker NUBP1, which encodes an ATP binding protein that regulates centrosome dynamics, microtubule organization and actin cytoskeleton (Schnatwinkel and Niswander, 2012; Ioannou et al., 2013), as well as the putative state marker $C E N P O$, within which an SNP loci has been associated with cognitive performance at the genome-wide significance level (Trampush et al., 2017). CENPO encodes a component of the interphase centromere complex, and is therefore involved in the cell cycle, one of the most dysregulated cellular processes we found for UCMS paradigm (Figure 3C). Cell cycle regulation is one of the mechanisms underlying the response to anti- and pro-neurogenic stimuli in major depression (Klempan et al., 2009; Patricio et al., 2013).

Using an animal model provides a more homogeneous genetic background to decipher pathophysiological mechanisms involved in disease evolution and its treatment, compared to using human subjects. Nevertheless, we could observe that variabilities in behavior also exist among laboratory mice, something that has not been extensively examined and tend to be minimized. An explanation for the discrepancies in behaviors within a very similar genetic background may be related to the epigenetic mechanisms by which chromatin structure and nucleosome positions are specified and maintained, as recently shown by Sun et al. $(2013,2015)$ for the development of susceptibility to depression and regulation of stress-related behaviors. Accordingly, Lepack et al. (2016) have recently reported a role for histone variants $\mathrm{H} 3.3$ dynamics in the nucleus accumbens in the regulation of aberrant social stressmediated gene expression and the precipitation of depressive-like behaviors in mice. Indeed, our microarray data are concordant with their results, as we detected in the blood of UCMS mice a significant decrease of $H 3 F 3 a$, which is restored after fluoxetine treatment, concomitant with an opposite pattern of expression for $H 3 F 3 b$ (data not shown). Moreover, we designed our study with the assumption that variations of gene expression in specific areas of the nervous system, as well as within specific cell types such as neuronal or glial cells, are mirrored by variations in the same genes in white blood cells. We do not know how cells with very different functions could have similarities in gene expression patterns and whether such patterns of expression would have any specific function for blood cells, or whether just represent a marker of a specific state of the body. One epigenetic mechanism that could be involved in conveying information from the central nervous system to the periphery involves the production, dissemination and engulfment of microRNAs that have the ability to modulate expression of hundreds of proteinencoding genes over long distances, similar to the mechanism of action of hormones (Cortez et al., 2011). Recent reports have described the role of these small RNAs in stress response, resiliency, and psychiatric disorders (Issler and Chen, 2015). It will be important in the future to establish, in the context of major depression pathophysiology, how small RNAs functionally link specific cell-types in the central nervous system, to blood cells in the periphery of the body.

We learned from the epigenomics field that DNA and RNA modifications occur in relation to environmental interactions in a dynamic fashion (Nagy and Turecki, 2012). Therefore, the above observations also emphasize the need to evaluate the pattern of RNA expression and modification at different time points. Such a task is absolutely impossible when relying on postmortem samples. It is therefore important to obtain and analyze blood samples collected from MDE patients and matching healthy control subjects over extended periods of time.

Our study has several limitations. The majority of rodent studies involving behavioral analyses used male rodents, despite a higher prevalence of MDD in women. Future investigations will require the inclusion of both sexes in animal testing (Hodes et al., 2017), but it is interesting to note that in a mouse model of depression during menopause, Miyata et al. (2016b) also found that the gene expression alterations induced by ovariectomy were mainly associated with ribosomal and mitochondrial functions in both the medial prefrontal cortex and the blood, strengthening the results we discussed above. We also only addressed the response to antidepressant treatment with a single drug, fluoxetine, while other drugs with different selectivity for neurotransmitters other than serotonin are frequently used in the clinic (Bagot et al., 2017). Other modalities such as repeated transcranial magnetic stimulation have been increasingly 
proposed, especially to patients resistant to first and second-line antidepressant drug treatments. Further investigations with various drugs and/or tools are thus warranted. We also classified animals as a responder or nonresponder according to a limited set of behavioral testing. Although it is not a trivial task to correlate the human antidepressant responses to that of rodents, additional behavioral testing could assess various dimensions of disease. Moreover, the stratification of stressed animals into responders and nonresponders yielded one group with only three animals. We thus cannot exclude that part of our analysis is underpowered and would require replication with larger groups of animals. In addition, it would be useful to retrieve blood profiling at the peak of the depressive symptoms and not just after a fixed period of time as there is an inter-individual variability in stress susceptibility. Finally, it will be necessary to repeat these experiments in several human cohorts, especially because large cohorts of patients are required for statistical power. It will also be important to assess the robustness of biomarker candidates by controlling for age, sex and the history of trauma, including the childhood trauma and the stress during the prior year.

In conclusion, our study confirms the power of using blood samples collected during antidepressant treatment to study a psychiatric disorder and validate the applicability of animal models to human disease in identifying targets and pathways for the design of biomarkers and novel therapeutics. Future studies should focus on biological pathways related to dynamics of genetic and epigenetic activation and repression, as targets for possible biomarkers and novel therapeutics.

\section{AUTHOR CONTRIBUTIONS}

$\mathrm{CB}$ and ECI designed the study. $\mathrm{CB}, \mathrm{RB}$ and ECI obtained funding for the study. A-MLG and SL conducted the UCMS

\section{REFERENCES}

American Psychiatric Association. (2000). Diagnostic and Statistical Manual of Mental Disorders, Fourth Edition, Text Revision (DSM-IV-TR). Arlington, VA: American Psychiatric Association.

American Psychiatric Association. (2008). Handbook of Psychiatric Measures. Washington, DC: American Psychiatric Association (APA).

Andrus, B. M., Blizinsky, K., Vedell, P. T., Dennis, K., Shukla, P. K., Schaffer, D. J., et al. (2012). Gene expression patterns in the hippocampus and amygdala of endogenous depression and chronic stress models. Mol. Psychiatry 17, 49-61. doi: 10.1038/mp.2010.119

Arloth, J., Bogdan, R., Weber, P., Frishman, G., Menke, A., Wagner, K. V., et al. (2015). Genetic differences in the immediate transcriptome response to stress predict risk-related brain function and psychiatric disorders. Neuron 86, 1189-1202. doi: 10.1016/j.neuron. 2015.05.034

Bagot, R. C., Cates, H. M., Purushothaman, I., Lorsch, Z. S., Walker, D. M., Wang, J., et al. (2016). Circuit-wide transcriptional profiling reveals brain region-specific gene networks regulating depression susceptibility. Neuron 90, 969-983. doi: 10.1016/j.neuron.2016.04.015

Bagot, R. C., Cates, H. M., Purushothaman, I., Vialou, V., Heller, E. A., Yieh, L., et al. (2017). Ketamine and imipramine reverse transcriptional signatures of susceptibility and induce resilience-specific gene expression profiles. Biol. Psychiatry 81, 285-295. doi: 10.1016/j.biopsych. 2016.06.012 procedures. $\mathrm{MH}$ and ECI extracted total RNAs from mice tissues. M-NL, WE-H and RB recruited the human subjects. ECI extracted total RNA from the human cohort. $\mathrm{MH}$ and NF-N performed microarray procedures. AB conducted all bioinformatic analysis related to microarray raw data and data uploading on a public database. $\mathrm{MH}$ performed the RT-qPCR experiments. J-LC and RB collected the human clinical data. J-LC performed the statistical analyses. $\mathrm{MH}$ and ECI analyzed the results and wrote the manuscript. All authors approved the final version of the manuscript.

\section{FUNDING}

The funding for this study was provided by a National Hospital Clinical Research Program (PHRC, No. 2010-19) as well as by the French Government (National Research Agency, ANR) through the VASPAC (ANR-13-SAMA-0002) and the SSRiD (ANR-15-EPIG-0003-03) projects. Differential Gene Expression was performed at the TGML Platform, supported by grants from INSERM, GIS IBiSA, Aix-Marseille Université, and ANR-10INBS-0009-10.

\section{ACKNOWLEDGMENTS}

The authors thank José Boucraut, Coraline Gadras and Samira Miloudi for the collection of the human biological samples. We also thank Jeanne Hsu for editing the manuscript.

\section{SUPPLEMENTARY MATERIAL}

The Supplementary Material for this article can be found online at: http://journal.frontiersin.org/article/10.3389/fnmol.2017.002 48/full\#supplementary-material

Belzeaux, R., Bergon, A., Jeanjean, V., Loriod, B., Formisano-Tréziny, C. Verrier, L., et al. (2012). Responder and nonresponder patients exhibit different peripheral transcriptional signatures during major depressive episode. Transl. Psychiatry 2:e185. doi: 10.1038/tp.2012.112

Bengsch, F., Tu, Z., Tang, H.-Y., Zhu, H., Speicher, D. W., and Zhang, R. (2015). Comprehensive analysis of the ubiquitinome during oncogeneinduced senescence in human fibroblasts. Cell Cycle 14, 1540-1547. doi: 10.1080/15384101.2015.1026492

Bertsch, B., Ogden, C. A., Sidhu, K., Le-Niculescu, H., Kuczenski, R., and Niculescu, A. B. (2005). Convergent functional genomics: a Bayesian candidate gene identification approach for complex disorders. Methods 37, 274-279. doi: 10.1016/j. ymeth.2005.03.012

Breen, M. S., Stein, D. J., and Baldwin, D. S. (2016). Systematic review of blood transcriptome profiling in neuropsychiatric disorders: guidelines for biomarker discovery. Hum. Psychopharmacol. 31, 373-381. doi: 10.1002/hu p. 2546

Breitenstein, B., Scheuer, S., and Holsboer, F. (2014). Are there meaningful biomarkers of treatment response for depression? Drug Discov. Today 19, 539-561. doi: 10.1016/j.drudis.2014.02.002

Chuang, J. C., Cui, H., Mason, B. L., Mahgoub, M., Bookout, A. L., Yu, H. G., et al. (2010). Chronic social defeat stress disrupts regulation of lipid synthesis. J. Lipid Res. 51, 1344-1353. doi: 10.1194/jlr.m002196

Cortez, M. A., Bueso-Ramos, C., Ferdin, J., Lopez-Berestein, G., Sood, A. K., and Calin, G. A. (2011). MicroRNAs in body fluids-the mix of hormones 
and biomarkers. Nat. Rev. Clin. Oncol. 8, 467-477. doi: 10.1038/nrclinonc. 2011.76

Crozatier, C., Farley, S., Mansuy, I. M., Dumas, S., Giros, B., and Tzavara, E. T. (2007). Calcineurin (protein phosphatase 2B) is involved in the mechanisms of action of antidepressants. Neuroscience 144, 1470-1476. doi: 10.1016/j. neuroscience.2006.11.030

Darby, M. M., Yolken, R. H., and Sabunciyan, S. (2016). Consistently altered expression of gene sets in postmortem brains of individuals with major psychiatric disorders. Transl. Psychiatry 6:e890. doi: 10.1038/tp.20 16.173

Daskalakis, N. P., Cohen, H., Cai, G., Buxbaum, J. D., and Yehuda, R. (2014). Expression profiling associates blood and brain glucocorticoid receptor signaling with trauma-related individual differences in both sexes. Proc. Natl. Acad. Sci. U S A 111, 13529-13534. doi: 10.1073/pnas. 1401660111

Davis, J., Maes, M., Andreazza, A., McGrath, J. J., Tye, S. J., and Berk, M. (2015). Towards a classification of biomarkers of neuropsychiatric disease: from encompass to compass. Mol. Psychiatry 20, 152-153. doi: 10.1038/mp. 2014.139

De Planell-Saguer, M., Schroeder, D. G., Rodicio, M. C., Cox, G. A., and Mourelatos, Z. (2009). Biochemical and genetic evidence for a role of IGHMBP2 in the translational machinery. Hum. Mol. Genet. 18, 2115-2126. doi: $10.1093 / \mathrm{hmg} / \mathrm{ddp} 134$

Descalzi, G., Mitsi, V., Purushothaman, I., Gaspari, S., Avrampou, K., Loh, Y. E., et al. (2017). Neuropathic pain promotes adaptive changes in gene expression in brain networks involved in stress and depression. Sci. Signal. 10:eaaj1549. doi: 10.1126/scisignal.aaj1549

Garbett, K. A., Vereczkei, A., Kálmán, S., Wang, L., Korade, Ž., Shelton, R. C., et al. (2015). Fibroblasts from patients with major depressive disorder show distinct transcriptional response to metabolic stressors. Transl. Psychiatry 5:e523. doi: $10.1038 /$ tp.2015.14

Girardi, P., Pompili, M., Innamorati, M., Mancini, M., Serafini, G., Mazzarini, L., et al. (2009). Duloxetine in acute major depression: review of comparisons to placebo and standard antidepressants using dissimilar methods. Hum. Psychopharmacol. 24, 177-190. doi: 10.1002/hup. 1005

Gormanns, P., Mueller, N. S., Ditzen, C., Wolf, S., Holsboer, F., and Turck, C. W. (2011). Phenome-transcriptome correlation unravels anxiety and depression related pathways. J. Psychiatr. Res. 45, 973-979. doi: 10.1016/j.jpsychires. 2010.12.010

Guilloux, J. P., Bassi, S., Ding, Y., Walsh, C., Turecki, G., Tseng, G., et al. (2015). Testing the predictive value of peripheral gene expression for nonremission following citalopram treatment for major depression. Neuropsychopharmacology 40, 701-710. doi: 10.1038/npp.2014.226

Gururajan, A., Clarke, G., Dinan, T. G., and Cryan, J. F. (2016). Molecular biomarkers of depression. Neurosci. Biobehav. Rev. 64, 101-133. doi: 10.1016/j. neubiorev.2016.02.011

Hestad, K. A., Engedal, K., Whist, J. E., Aukrust, P., Farup, P. G., Mollnes, T. E., et al. (2016). Patients with depression display cytokine levels in serum and cerebrospinal fluid similar to patients with diffuse neurological symptoms without a defined diagnosis. Neuropsychiatr. Dis. Treat. 12, 817-822. doi: $10.2147 /$ ndt.s101925

Hodes, G. E., Walker, D. M., Labonté, B., Nestler, E. J., and Russo, S. J. (2017). Understanding the epigenetic basis of sex differences in depression. J. Neurosci. Res. 95, 692-702. doi: 10.1002/jnr.23876

Huang Da, W., Sherman, B. T., and Lempicki, R. A. (2009). Systematic and integrative analysis of large gene lists using DAVID bioinformatics resources. Nat. Protoc. 4, 44-57. doi: 10.1038/nprot.2008.211

Ioannou, A., Santama, N., and Skourides, P. A. (2013). Xenopus laevis nucleotide binding protein 1 ( $\mathrm{xNubp} 1$ ) is important for convergent extension movements and controls ciliogenesis via regulation of the actin cytoskeleton. Dev. Biol. 380, 243-258. doi: 10.1016/j.ydbio.2013.05.004

Issler, O., and Chen, A. (2015). Determining the role of microRNAs in psychiatric disorders. Nat. Rev. Neurosci. 16, 201-212. doi: 10.1038/nrn3879

Issler, O., Haramati, S., Paul, E. D., Maeno, H., Navon, I., Zwang, R., et al. (2014). MicroRNA 135 is essential for chronic stress resiliency, antidepressant efficacy, and intact serotonergic activity. Neuron 83, 344-360. doi: 10.1016/j.neuron. 2014.05.042
Jaworska, N., Yang, X. R., Knott, V., and Macqueen, G. (2015). A review of fMRI studies during visual emotive processing in major depressive disorder. World J. Biol. Psychiatry 16, 448-471. doi: 10.3109/15622975.2014. 885659

Jentsch, M. C., Van Buel, E. M., Bosker, F. J., Gladkevich, A. V., Klein, H. C., Oude Voshaar, R. C., et al. (2015). Biomarker approaches in major depressive disorder evaluated in the context of current hypotheses. Biomark. Med. 9, 277-297. doi: 10.2217/bmm.14.114

Joeyen-Waldorf, J., Nikolova, Y. S., Edgar, N., Walsh, C., Kota, R., Lewis, D. A., et al. (2012). Adenylate cyclase 7 is implicated in the biology of depression and modulation of affective neural circuitry. Biol. Psychiatry 71, 627-632. doi: 10.1016/j.biopsych.2011.11.029

Kessler, R. C. (2003). Epidemiology of women and depression. J. Affect. Disord. 74, 5-13. doi: 10.1016/s0165-0327(02)00426-3

Klempan, T. A., Sequeira, A., Canetti, L., Lalovic, A., Ernst, C., ffrench-Mullen, J., et al. (2009). Altered expression of genes involved in ATP biosynthesis and GABAergic neurotransmission in the ventral prefrontal cortex of suicides with and without major depression. Mol. Psychiatry 14, 175-189. doi: 10.1038/sj.mp. 4002110

Kohen, R., Dobra, A., Tracy, J. H., and Haugen, E. (2014). Transcriptome profiling of human hippocampus dentate gyrus granule cells in mental illness. Transl. Psychiatry 4:e366. doi: 10.1038/tp.2014.9

Lepack, A. E., Bagot, R. C., Peña, C. J., Loh, Y. E., Farrelly, L. A., Lu, Y., et al. (2016). Aberrant $\mathrm{H} 3.3$ dynamics in NAc promote vulnerability to depressive-like behavior. Proc. Natl. Acad. Sci. U S A 113, 12562-12567. doi: 10.1073/pnas. 1608270113

Leuchter, A. F., Cook, I. A., Hamilton, S. P., Narr, K. L., Toga, A., Hunter, A. M., et al. (2010). Biomarkers to predict antidepressant response. Curr. Psychiatry Rep. 12, 553-562. doi: 10.1007/s11920-010-0160-4

Livak, K. J., and Schmittgen, T. D. (2001). Analysis of relative gene expression data using real-time quantitative PCR and the $2^{-\Delta \Delta \mathrm{C}_{\mathrm{T}}}$ method. Methods 25 , 402-408. doi: 10.1006/meth.2001.1262

Malki, K., Pain, O., Tosto, M. G., Du Rietz, E., Carboni, L., and Schalkwyk, L. C. (2015). Identification of genes and gene pathways associated with major depressive disorder by integrative brain analysis of rat and human prefrontal cortex transcriptomes. Transl. Psychiatry 5:e519. doi: 10.1038/tp. 2015.15

McMahon, F. J. (2014). Prediction of treatment outcomes in psychiatry-where do we stand? Dialogues Clin. Neurosci. 16, 455-464.

McNeely, K. C., Cupp, T. D., Little, J. N., Janisch, K. M., Shrestha, A., and Dwyer, N. D. (2017). Mutation of Kinesin-6 Kif20b causes defects in cortical neuron polarization and morphogenesis. Neural Dev. 12:5. doi: 10.1186/s13064-017-0082-5

Mehta-Raghavan, N. S., Wert, S. L., Morley, C., Graf, E. N., and Redei, E. E. (2016). Nature and nurture: environmental influences on a genetic rat model of depression. Transl. Psychiatry 6:e770. doi: 10.1038/tp.2016.28

Miyata, S., Kurachi, M., Okano, Y., Sakurai, N., Kobayashi, A., Harada, K., et al. (2016a). Blood transcriptomic markers in patients with late-onset major depressive disorder. PLoS One 11:e0150262. doi: 10.1371/journal.pone.0150262

Miyata, S., Kurachi, M., Sakurai, N., Yanagawa, Y., Ishizaki, Y., Mikuni, M., et al. (2016b). Gene expression alterations in the medial prefrontal cortex and blood cells in a mouse model of depression during menopause. Heliyon 2:e00219. doi: 10.1016/j.heliyon.2016.e00222

Möller, H. J. (2008). Outcomes in major depressive disorder: the evolving concept of remission and its implications for treatment. World J. Biol. Psychiatry 9, 102-114. doi: 10.1080/15622970801981606

Moylan, S., Maes, M., Wray, N. R., and Berk, M. (2013). The neuroprogressive nature of major depressive disorder: pathways to disease evolution and resistance and therapeutic implications. Mol. Psychiatry 18, 595-606. doi: $10.1038 / \mathrm{mp} .2012 .33$

Nagy, C., and Turecki, G. (2012). Sensitive periods in epigenetics: bringing us closer to complex behavioral phenotypes. Epigenomics 4, 445-457. doi: 10.2217/epi.12.37

Nollet, M., Le Guisquet, A. M., and Belzung, C. (2013). Unit 5.65 Models of depression: unpredictable chronic mild stress in mice. Curr. Protoc. Pharmacol. 61, 5.65.1-5.65.17. doi: 10.1002/0471141755.ph0565s61

Pajer, K., Andrus, B. M., Gardner, W., Lourie, A., Strange, B., Campo, J., et al. (2012). Discovery of blood transcriptomics markers for depression in animal 
models and pilot validation in subjects with early-onset major depression. Transl. Psychiatry 2:e101. doi: 10.1038/tp.2012.26

Papakostas, G. I., and Fava, M. (2008). Predictors, moderators, and mediators (correlates) of treatment outcome in major depressive disorder. Dialogues Clin. Neurosci. 10, 439-451.

Park, D. I., Dournes, C., Sillaber, I., Ising, M., Asara, J. M., Webhofer, C., et al. (2017). Delineation of molecular pathway activities of the chronic antidepressant treatment response suggests important roles for glutamatergic and ubiquitin-proteasome systems. Transl. Psychiatry 7:e1078. doi: 10.1038/tp. 2017.39

Patricio, P., Mateus-Pinheiro, A., Sousa, N., and Pinto, L. (2013). Re-cycling paradigms: cell cycle regulation in adult hippocampal neurogenesis and implications for depression. Mol. Neurobiol. 48, 84-96. doi: 10.1007/s12035013-8422-x

Phillips, M. L., Chase, H. W., Sheline, Y. I., Etkin, A., Almeida, J. R., Deckersbach, T., et al. (2015). Identifying predictors, moderators, and mediators of antidepressant response in major depressive disorder: neuroimaging approaches. Am. J. Psychiatry 172, 124-138. doi: 10.1176/appi. ajp.2014.14010076

Plaisier, S. B., Taschereau, R., Wong, J. A., and Graeber, T. G. (2010). Rank-rank hypergeometric overlap: identification of statistically significant overlap between gene-expression signatures. Nucleic. Acids Res. 38:e169. doi: 10.1093/nar/gkq636

Qesseveur, G., Petit, A. C., Nguyen, H. T., Dahan, L., Colle, R., Rotenberg, S., et al. (2016). Genetic dysfunction of serotonin $2 \mathrm{~A}$ receptor hampers response to antidepressant drugs: a translational approach. Neuropharmacology 105, 142-153. doi: 10.1016/j.neuropharm.2015.12.022

Redei, E. E., Andrus, B. M., Kwasny, M. J., Seok, J., Cai, X., Ho, J., et al. (2014). Blood transcriptomic biomarkers in adult primary care patients with major depressive disorder undergoing cognitive behavioral therapy. Transl. Psychiatry 4:e442. doi: 10.1038/tp.2014.66

Redei, E. E., and Mehta, N. S. (2015). Blood transcriptomic markers for major depression: from animal models to clinical settings. Ann. N Y Acad. Sci. 1344, 37-49. doi: $10.1111 /$ nyas. 12748

Regenold, W. T., Pratt, M., Nekkalapu, S., Shapiro, P. S., Kristian, T., and Fiskum, G. (2012). Mitochondrial detachment of hexokinase 1 in mood and psychotic disorders: implications for brain energy metabolism and neurotrophic signaling. J. Psychiatr. Res. 46, 95-104. doi: 10.1016/j.jpsychires. 2011.09.018

Rive, M. M., van Rooijen, G., Veltman, D. J., Phillips, M. L., Schene, A. H., and Ruhé, H. G. (2013). Neural correlates of dysfunctional emotion regulation in major depressive disorder. A systematic review of neuroimaging studies. Neurosci. Biobehav. Rev. 37, 2529-2553. doi: 10.1016/j.neubiorev.2013.07.018

Schnatwinkel, C., and Niswander, L. (2012). Nubp1 is required for lung branching morphogenesis and distal progenitor cell survival in mice. PLoS One 7:e44871. doi: 10.1371/journal.pone.0044871

Seimandi, M., Seyer, P., Park, C. S., Vandermoere, F., Chanrion, B., Bockaert, J., et al. (2013). Calcineurin interacts with the serotonin transporter C-terminus to modulate its plasma membrane expression and serotonin uptake. J. Neurosci. 33, 16189-16199. doi: 10.1523/JNEUROSCI.0076-13.2013

Sibille, E., Arango, V., Galfalvy, H. C., Pavlidis, P., Erraji-Benchekroun, L., Ellis, S. P., et al. (2004). Gene expression profiling of depression and suicide in human prefrontal cortex. Neuropsychopharmacology 29, 351-361. doi: 10.1038/sj.npp.1300335
Sibille, E., Wang, Y., Joeyen-Waldorf, J., Gaiteri, C., Surget, A., Oh, S., et al. (2009). A molecular signature of depression in the amygdala. Am. J. Psychiatry 166, 1011-1024. doi: 10.1176/appi.ajp.2009.08121760

Sun, H., Damez-Werno, D. M., Scobie, K. N., Shao, N. Y., Dias, C., Rabkin, J., et al. (2015). ACF chromatin-remodeling complex mediates stress-induced depressive-like behavior. Nat. Med. 21, 1146-1153. doi: 10.1038/nm.3939

Sun, H., Kennedy, P. J., and Nestler, E. J. (2013). Epigenetics of the depressed brain: role of histone acetylation and methylation. Neuropsychopharmacology 38, 124-137. doi: 10.1038/npp.2012.73

Surget, A., Saxe, M., Leman, S., Ibarguen-Vargas, Y., Chalon, S., Griebel, G., et al. (2008). Drug-dependent requirement of hippocampal neurogenesis in a model of depression and of antidepressant reversal. Biol. Psychiatry 64, 293-301. doi: 10.1016/j.biopsych.2008.02.022

Tobe, E. H. (2013). Mitochondrial dysfunction, oxidative stress, and major depressive disorder. Neuropsychiatr. Dis. Treat. 9, 567-573. doi: 10.2147/NDT. s44282

Trampush, J. W., Yang, M. L., Yu, J., Knowles, E., Davies, G., Liewald, D. C., et al. (2017). GWAS meta-analysis reveals novel loci and genetic correlates for general cognitive function: a report from the COGENT consortium. Mol. Psychiatry 22, 336-345. doi: 10.1038/mp.2016.244

Volland, C., Bremer, S., Hellenkamp, K., Hartmann, N., Dybkova, N., Khadjeh, S., et al. (2016). Enhanced cardiac TBC1D10C expression lowers heart rate and enhances exercise capacity and survival. Sci. Rep. 6:33853. doi: $10.1038 /$ srep33853

Wan, Y., Liu, Y., Wang, X., Wu, J., Liu, K., Zhou, J., et al. (2015). Identification of differential microRNAs in cerebrospinal fluid and serum of patients with major depressive disorder. PLoS One 10:e0121975. doi: 10.1371/journal.pone.0121975

Wise, T., Radua, J., Via, E., Cardoner, N., Abe, O., Adams, T. M., et al. (2016). Common and distinct patterns of grey-matter volume alteration in major depression and bipolar disorder: evidence from voxel-based meta-analysis. Mol. Psychiatry doi: 10.1038/mp.2016.72 [Epub ahead of print].

Wong, G. T., Chang, R. C., and Law, A. C. (2013). A breach in the scaffold: the possible role of cytoskeleton dysfunction in the pathogenesis of major depression. Ageing Res. Rev. 12, 67-75. doi: 10.1016/j.arr.2012.08.004

Yoo, S. W., Motari, M. G., Susuki, K., Prendergast, J., Mountney, A., Hurtado, A., et al. (2015). Sialylation regulates brain structure and function. FASEB J. 29, 3040-3053. doi: 10.1096/fj.15-270983

Young, J. J., Silber, T., Bruno, D., Galatzer-Levy, I. R., Pomara, N., and Marmar, C. R. (2016). Is there progress? An overview of selecting biomarker candidates for major depressive disorder. Front. Psychiatry 7:72. doi: $10.3389 /$ fpsyt.2016.00072

Conflict of Interest Statement: The authors declare that the research was conducted in the absence of any commercial or financial relationships that could be construed as a potential conflict of interest.

Copyright (๔) 2017 Hervé, Bergon, Le Guisquet, Leman, Consoloni, FernandezNunez, Lefebvre, El-Hage, Belzeaux, Belzung and Ibrahim. This is an open-access article distributed under the terms of the Creative Commons Attribution License (CC BY). The use, distribution or reproduction in other forums is permitted, provided the original author(s) or licensor are credited and that the original publication in this journal is cited, in accordance with accepted academic practice. No use, distribution or reproduction is permitted which does not comply with these terms. 